\title{
A Case of Middle Cerebral Artery Occlusion Due to Thrombus with Bacterial Colony
}

\author{
Emi Kuriyama ${ }^{1 *}$, Katsuhisa Hirayama ${ }^{2}$, Keita Terui $^{2}$, Naoki Tsuji ${ }^{2}$ and Naoyuki Nakao ${ }^{1}$ \\ ${ }^{1}$ Department of Neurosurgery of Wakayama Medical University, Japan \\ ${ }^{2}$ Department of Neurosurgery of Naga Municipal Hospital, Japan \\ *Corresponding author: Emi Kuriyama, Department of Neurosurgery of Wakayama Medical University, Japan
}

\section{ARTICLE INFO}

Received: March 26, 2020

Published: 幽 April 17, 2020

Citation: Emi K, Katsuhisa H, Keita T, Naoki T, Naoyuki N. A Case of Middle Cerebral Artery Occlusion Due to Thrombus with Bacterial Colony. Biomed J Sci \& Tech Res 27(1)-2020. BJSTR. MS.ID.004447.

\author{
ABSTRACT
}

Diagnosis and treatment for embolic stroke due to Infective Endocarditis (IE) is the challenging. We describe the case of acute middle cerebral artery occlusion with fever and inflammation underwent Mechanical Thrombectomy (MT) and retrieved atypical thrombus. That pathological finding, thrombus with bacterial colony, proved the diagnosis of IE. Following appropriate antibiotic therapy and replacement of the cardiac valve, the clinical outcome was favorable. Given this case experience and other reported cases, MT may be considered as a prime option for acute ischemic large-vessel occlusion due to IE.

Keywords: Acute Ischemic Stroke; Middle Cerebral Artery Occlusion; Infective Endocarditis (IE); Mechanical Thrombectomy (MT)

\section{Introduction}

Embolic stroke due to Infective Endocarditis (IE) is the most common neurological complication and the cause of high morbidity and mortality especially in the case of a large-vessel occlusion. It often develops as a first symptom of IE. Therefore, fast appropriate diagnosis and treatment are needed to improve clinical outcomes of the patients. Successful Mechanical Thrombectomy (MT) have been published recently. We present the case of acute middle cerebral artery occlusion treated with MT and retrieved atypical thrombus, proved the diagnosis of IE.

\section{Case Report}

A 69-year-old woman presented with fever $\left(39^{\circ} \mathrm{C}\right)$, dysarthria, right conjugate deviation of the eyes, and left hemiparesis (National Institutes of Health Stroke Scale (NIHSS) score 13). She has been treated with Warfarin because of having medical history of atrial fibrillation and pulmonary embolism. The white blood cells count was $10490 / \mu \mathrm{L}$, the C-reactive protein was $8.31 \mathrm{mg} / \mathrm{dl}$, prothrombin time-International Normalized Ratio (PT-INR) was 2.61 and BNP was $272.52 \mathrm{pg} / \mathrm{ml}$. A diffusion-weighted image showed (Figure 1A). Magnetic resonance angiography showed the middle cerebral artery (M1) occlusion (Figure 1B). She was underwent MT (Figure 1C). Trevo $4 * 20 \mathrm{~mm}$ stent retriever (Stryker Neurovascular Fremont, CA, USA) was deployed across the thrombus and continuous aspiration prior to intracranial vascular embolectomy technique by Penumbra 5MAX (Penumbra Inc., Alameda, CA, USA) was performed (Figure 1D). However, no recanalization was obtained. Then, a simple aspiration by Penumbra 5MAXwas conducted (Figure 1E).

\section{Results}

The firm white thrombus was retrieved and Thrombolysis In Cerebral Infarction (TICI) 2Bwas achieved (Figure 1F). On the second hospital day, transthoracic echocardiogram detected the vegetation $\left(7^{*} 14 \mathrm{~mm}\right)$ on the mitral valve and blood cultures grew staphylococcus lugdunensis. As a result, antibiotic therapy was started. The pathology of retrieved thrombus was bacterial colony with neutrophils (Figure $1 \mathrm{G} \& 1 \mathrm{H}$ ). She transferred cardiovasucular surgery center to replace the mitral valve on NIHSSO. 

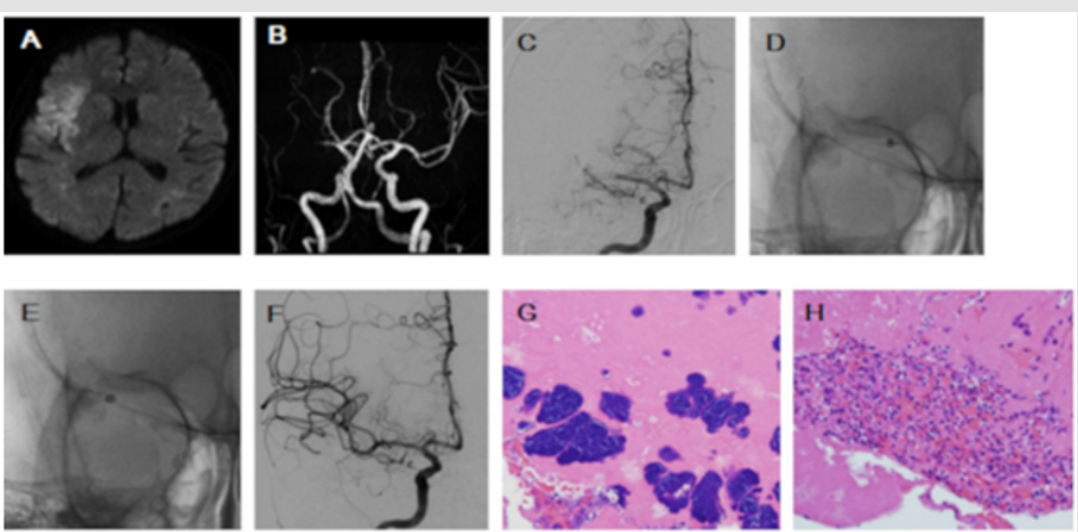

Figure 1:

A. Axial diffusion weighted image shows a hyperintense lesion in the right frontal and temporal cortical lesion.

B. Magnetic resonance angiography shows the right M1 occlusion.

C. Pre-treatment right internal carotid angiography shows the right M1 occlusion.

D. Trevo $4 * 20 \mathrm{~mm}$ stent retriever was deployed across the thrombus and Penumbra 5MAX was navigated just proximal of thrombus. After no retrograde blood was identified, Penumbra 5MAX and stent retriever were withdrawn under continuous aspiration.

E. For the second time Penumbra 5MAX was navigated just proximal of thrombus and a direct aspiration was conducted.

F. Good recanalization of the middle cerebral artery was achieved on the final angiography.

G,H. Hematoxylin-Eosin stain $(200 \times)$ where many bacterial colonies and vast amounts of neutrophils are seen in the thrombus.

\section{Discussion}

Clinical symptoms suspicious IE in this case were fever inflammation and atypical white thrombus regardless of good control of PT-INR. IE related ischemic stroke often develops before the diagnosis of IE [1]. Therefore transthoracic/transesophageal echocardiogram and blood cultures should be done at an initial stage after hospitalization. MT can be effective for two reasons. One is good outcomes are expected. Among the 27 cases from reported literature review, successful recanalization (TICI2B-3) achieved 18 cases (67\%) and NIHSS improved after MT except for two cases [2]. Moreover, few cases occurred symptomatic intracranial hemorrhages [3]. On the other hand intravenous tissue plasminogen activator is high risk of the complication of intracerebral hemorrhage [3-6]. Anotheris the pathology of the retrieved thrombus leads to definitive diagnosis for embolic stroke of unknown origin [7].

\section{Conclusion}

It is the most important to suspect IE related stroke in the case of examining stroke patients with fever and inflammation. MT may be safe, useful, and optimal option to treat an acute large-vessel occlusion due to IE. Macroscopic and histopathological findings of retrieved thrombus also contribute to confirm the definitive diagnosis and guide appropriate antibiotic therapy.

\section{References}

1. Snygg-Martin U, Gustafsson L, Rosengren L, Alsiö A, Ackerholm P, et al. (2008) Cerebrovascularcomplications in patients with left-sided infective endocarditis are common: A prospective study using magnetic resonance imaging and neurochemical brain damage markers. Clin Infect Dis 47: 23-30.

2. Sloane KL, Raymond SB, Rabinov JD, Singhal AB (2020) Mechanical Thrombectomy in Stroke from Infective Endocarditis: Case Report and Review. J Stroke Cerebrovasc Dis 29(1): 104501.

3. Marquardt RJ, Cho SM, Thatikunta P, Deshpande A, Wisco D, et al. (2019) Acute Ischemic Stroke Therapy in Infective Endocarditis: Case Series and Systematic Review. J Stroke Cerebrovasc Dis 28(8): 2207-2212.

4. Kim JM, Jeon JS, Kim YW, Kang DH, Hwang WH, et al. (2014) Forced arterial suction thrombectomy of septic embolic middle cerebral artery occlusion due to infective endocarditis: An illustrative case and review of the literature. Neurointervention 9: 101-105.

5. Brownlee WJ, Anderson NE, Barber PA (2014) Intravenous thrombolysis is unsafe in stroke due to infective endocarditis. Intern Med J 44(2): 195197.

6. Bhuva P, Kuo SH, Claude Hemphill J, Lopez GA (2010) Intracranial hemorrhage following thrombolytic use for stroke caused by infective endocarditis. Neurocrit Care 12(1): 79-82.

7. O`Connor KP, Perez GS, Ray B, Peterson JEG, Bohnstedt BN (2019) Histopathological examination of an embolus in infective endocarditis: Case report and review of literature. Interdisciplinary Neurosurg vol 18: 100471. 
ISSN: 2574-1241

DOI: 10.26717/BJSTR.2020.27.004447

Emi Kuriyama. Biomed J Sci \& Tech Res

(c) (- This work is licensed under Creative

Submission Link: https://biomedres.us/submit-manuscript.php

$\begin{array}{ll}\text { BIOMEDICAL } & \text { Assets of Publishing with us } \\ \text { RESEARCHES } & \text { - Global archiving of articles } \\ \text { - Immediate, unrestricted online access } \\ \text { - Rigorous Peer Review Process } \\ \text { https://biomedres.us/ }\end{array}$

